\title{
Within-session changes in responding during concurrent schedules that employ two different operanda
}

\author{
FRANCES K. MCSWEENEY, JEFFREY N. WEATHERLY, and JOHN M. ROLL \\ Washington State University, Pullman, Washington
}

\begin{abstract}
Five rats responded on several concurrent schedules in which pressing a key produced reinforcers in one component and pressing a lever produced reinforcers in the other component (Experiment 1). Four pigeons responded on several concurrent keypeck treadlepress schedules (Experiment 2). The programmed rates of reinforcement varied from 15 to 240 reinforcers per hour in different conditions. Rates of responding usually changed systematically within experimental sessions, and the changes were similar for the two components of a concurrent schedule. These results imply that within-session changes in responding may not confound the predictions of theories that describe the ratio of the rates of responding during the two components of concurrent schedules. Instead, withinsession changes may be controlled by a mechanism that integrates the reinforcers obtained from the two components.
\end{abstract}

The quantification of concurrent schedule responding has been a leading topic of research for many years (Herrnstein, 1970). The recent discovery of systematic changes in responding within sessions may cause problems for this quantification (McSweeney, Hatfield, \& Allen, 1990). Within-session changes in responding can be large and they occur for many species performing a variety of responses under many different conditions (McSweeney \& Roll, 1993), including concurrent schedules (McSweeney \& Hinson, 1992).

Within-session changes in responding create problems for any theory that attempts to predict the average rate at which subjects respond during a session (Herrnstein, 1970). Within-session changes suggest that such theories are incomplete, because they do not describe systematic changes in behavior at a more molecular level.

Within-session changes may create more troubling problems for quantification if they follow different patterns for the two components of a concurrent schedule. For example, many theories of concurrent schedule responding attempt to predict the ratio of the rates of responding during the two components averaged over the session (Baum, 1974; Herrnstein, 1970). Suppose that response rates in a concurrent schedule increase to a peak and then decrease within an experimental session,

The authors wish to thank John Hinson for his comments on this manuscript. This material is based on work supported by National Science Foundation Grant IBN-9207346. Portions of these results were presented at the May 1994 meeting of the Association for Behavior Analysis in Atlanta. Reprints may be obtained from F. K. McSweeney, Department of Psychology, Washington State University, Pullman, WA $99164-4820$.

-Accepted by previous editor, Vincent M. LoLordo as they do during multiple and simple schedules. Suppose also that the peak rate of responding occurs earlier in the session and that within-session changes are larger for components that provide higher (or richer) rates of reinforcement than for those that provide lower (or leaner) rates (McSweeney, 1992; McSweeney, Roll, \& Cannon, 1994; McSweeney, Roll, \& Weatherly, 1994). In this case, the ratio of the rates of responding during the two components will not be constant across a session; instead, the ratio of the richer to the leaner response rate will increase to a peak and then decrease across a session. If the peak rate of responding is reached at a constant time after the beginning of a session, the ratio of response rates also will differ for sessions of different lengths when the ratio is calculated across an entire session. This type of outcome is observed for multiple schedules when session length is varied (McSweeney, 1992; McSweeney, Roll, \& Cannon, 1994).

This instability in the ratio of response rates might not occur if responding changes similarly within the session for both components of concurrent schedules. Suppose, for example, that within-session changes in responding are produced by changes in a multiplier that modulates absolute rates at which subjects respond. If this multiplier changes in the same way within sessions for two components of a concurrent schedule, its effect will cancel when the ratio of the rates of responding is calculated.

In the present experiments, we examined whether responding would change systematically within sessions when rats (Experiment 1) and pigeons (Experiment 2) responded on concurrent schedules. We also determined whether such changes occurred similarly for the two components of the concurrent schedule. 


\section{EXPERIMENT 1}

Experiment 1 was an examination of within-session changes in responding when rats pressed a lever and a key for sweetened condensed milk on several two-component concurrent schedules. Different patterns of responding were encouraged in the two components in two ways. First, the rates of reinforcement associated with the components of the concurrent schedule differed by as much as a factor of 16 under different conditions. Such large differences in reinforcement rates produce substantial differences in within-session response patterning when subjects respond on simple or multiple schedules (McSweeney, 1992; McSweeney, Roll, \& Cannon, 1994; McSweeney, Roll, \& Weatherly, 1994). Second, we expected that the use of different operanda in each component of the concurrent schedule might produce different patterns of within-session responding in each component due to performance variables. For example, responding might increase early in a session because of a muscle warm-up effect, but then subsequently decrease from fatigue (e.g., Mosso, 1906). Because it seems unlikely that the muscles involved in key- and leverpressing warm up and fatigue at the same rate, within-session changes in responding should differ for the two components of a concurrent schedule, if such performance factors help to produce them.

\section{Method}

Subjects. The subjects were 5 male rats bred from SpragueDawley stock in the Johnson Tower Vivarium at Washington State University. They were approximately 120 days old at the start of the experiment. The rats were maintained at approximately $85 \%$ of their free-feeding body weights by postsession feedings. Water was freely available in the home cage.

Apparatus. The apparatus was a $21.0 \times 21.5 \times 24.0 \mathrm{~cm}$ enclosure equipped with a lever and a key. A 6-cm-diameter opening centered in the logic panel ( $4 \mathrm{~cm}$ above the floor) allowed access to a $0.25-\mathrm{ml}$ dipper. A $5-\mathrm{W}$ light was located behind a $2-\mathrm{cm}-$ diameter Plexiglas panel, $3 \mathrm{~cm}$ from each side of the logic panel and $5.5 \mathrm{~cm}$ from the top of the chamber. The light on the left side of the panel was clear; the one on the right was opaque. A $2.5-\mathrm{cm}-$ diameter Plexiglas key, which required a force of approximately $0.25 \mathrm{~N}$ for its operation, was located $2 \mathrm{~cm}$ below the left light. A $3.5-\mathrm{cm}$ lever, which required approximately $0.30 \mathrm{~N}$ for its operation, extended $2 \mathrm{~cm}$ into the chamber and was located $3 \mathrm{~cm}$ below the right light. The apparatus was enclosed in a sound-attenuating chamber. A SYM microcomputer located in another room presented experimental events and recorded data. A ventilating fan masked noises from outside the apparatus.

Procedure. Pressing of the key and the lever was shaped by a successive-approximations procedure. The rate of reinforcement produced by each response was gradually reduced until subjects responded on a variable-interval (VI) 60 -sec schedule.

During the first experimental condition, pressing the key and pressing the lever each produced reinforcers according to a VI 60 -sec schedule. Reinforcers were 5 -sec of access to the dipper, which contained sweetened condensed milk mixed in a ratio of $1: 1$ with water. Reinforcers were scheduled according to a 25 -interval Fleshler and Hoffman (1962) series. The session timer did not advance during reinforcement. A 3-sec changeover delay (COD) penalized all changes from one operandum to the other. The two lights located above the response operanda, as well as the house- light, were illuminated throughout the session except during reinforcement. Sessions lasted for $60 \mathrm{~min}$ and were conducted daily, five to six times per week.

After 30 sessions of training on the concurrent VI 60-sec VI 60 -sec schedule, all rats received 30 sessions of training on each of the following schedules in the following order: (1) concurrent VI 240-sec VI 15-sec; (2) concurrent VI 120-sec VI 30-sec; (3) concurrent VI 30-sec VI 120-sec; (4) concurrent VI 15-sec VI 240-sec; and (5) a concurrent VI 60-sec VI 60-sec schedule. Here and throughout this paper, the schedule obtained by pressing the key is listed first. The other schedule was obtained by pressing the lever. All other procedural details were similar to those for the initial concurrent VI 60-sec VI 60-sec schedule.

\section{Results and Discussion}

The procedure exerted good control over behavior. The rates of key- and leverpressing generally increased with increases in their programmed rates of reinforcement, but the rate of leverpressing declined at the highest rate. The average rates $( \pm S E M)$ of keypressing were 55.1 (7.8), $47.5(6.9), 43.2$ (8.5), $32.8(5.2), 16.3(5.0)$, and $1.0(0.6)$ responses per minute, respectively, for the VI 15-sec, VI 30-sec, VI 60-sec, VI 60-sec, VI 120-sec, and VI 240 -sec components. The average rates $( \pm S E M)$ of leverpressing were $26.2(3.3), 41.1$ (5.7), 22.8 (3.3), $24.7(3.1), 9.4(0.6)$, and $11.9(1.3)$ responses per minute, respectively, for each of the schedules listed above. Here and throughout this paper, all results have been averaged over all subjects during the last 5 sessions of each schedule condition. Decreases in responding at high programmed rates of reinforcement are frequently observed (Dougan \& McSweeney, 1985; McSweeney \& Melville, 1991), and they are consistent with several theories (Baum, 1981; Staddon, 1979).

Figure 1 presents the percentage of the total-session keypresses (circles) and leverpresses (triangles) during successive 5-min intervals for the mean of all subjects responding on each component of a concurrent schedule. Each panel presents the results for a different schedule. Percentages were calculated by dividing the mean number of responses during a 5-min interval by the mean total number of responses during the session and multiplying by 100 . Percentages were used so that differences in absolute rates of key- and leverpressing would not obscure similarities in the within-session patterns of responding the interested reader can use the results presented above to convert these percentages to absolute response rates.

Responding usually changed within the session for each component of the concurrent schedules, generally increasing to a peak and then decreasing, or decreasing throughout the session. One-way repeated measures analyses of variance (ANOVAs) applied to the rates of responding by individual subjects during successive 5-min intervals confirmed that the within-session changes in responding were significant for all components $[F \mathrm{~s}(11,44)$ $>3.30$, ps <.002], except for VI 240-sec components. Leverpressing changed significantly within sessions even during the VI 240 -sec component $[F(11,44)=$ $2.19, p<.033]$, but keypressing did not $[F(11,44)=$ $1.87, p<.070]$. In all cases (except for leverpressing 


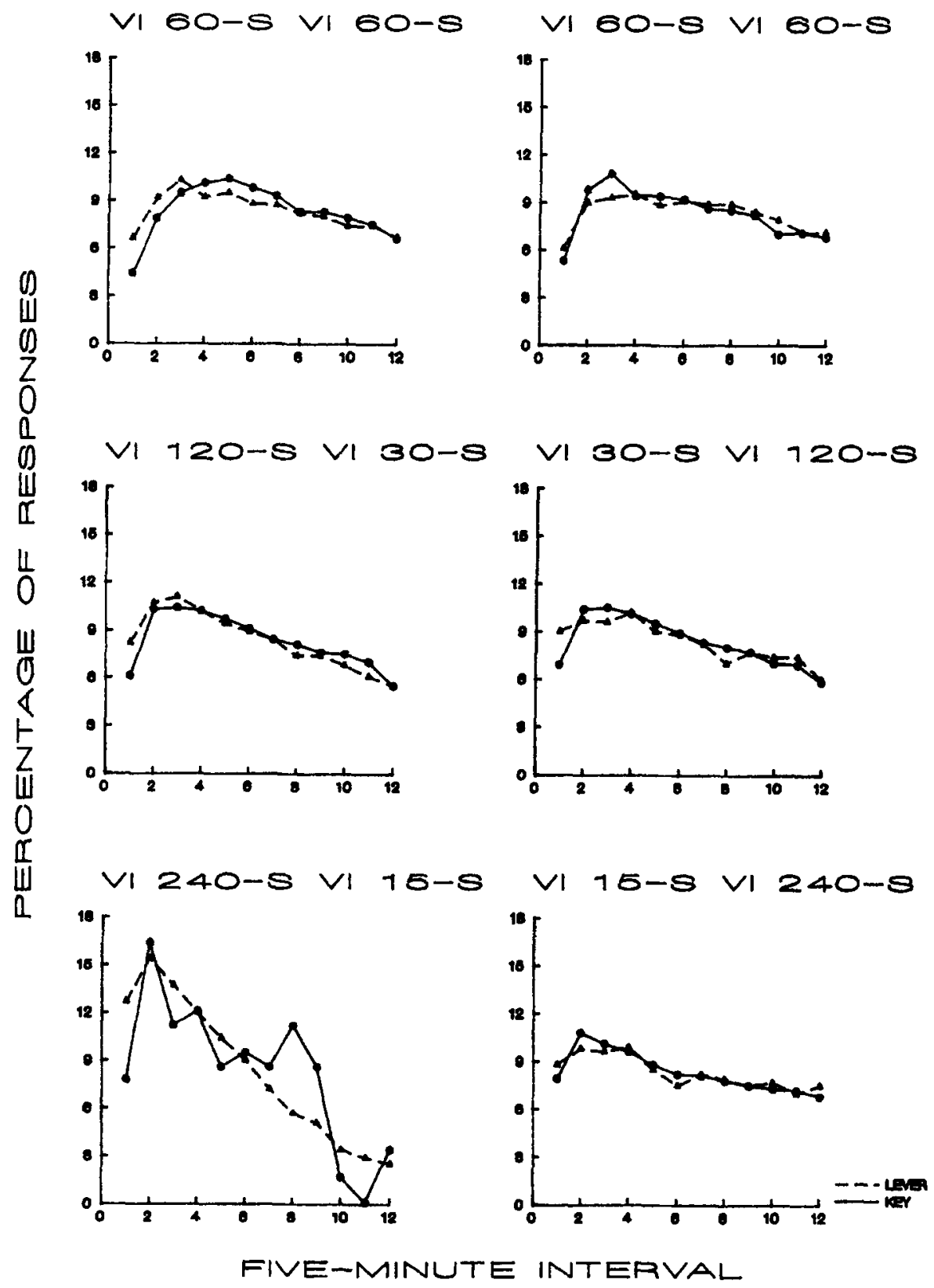

Figure 1. The percentage of the total-session keypresses (circles) and leverpresses (triangles) during successive 5-min intervals for the mean of all subjects responding on each concurrent schedule in Experiment 1 . The results are the means calculated over the last five sescions for which each schedule was presented. Each graph presents the results for a difierent schedule.

during the first VI 60-sec component and keypressing during the VI 120-sec component), significant changes also were accompanied by a significant $(p<.05)$ linear or quadratic polynomial contrast $[F \mathrm{~s}(1,4)>7.20]$. Significant contrasts indicate that the significant changes in responding within sessions also were systematic. Significant linear contrasts indicate that the significant within-session changes are best described as a decrease in responding. Significant quadratic contrasts indicate that the changes are bitonic.
A comparison of key and lever responding (Figure 1) indicated that within-session changes in responding were similar regardless of the operandum that produced the reinforcer. These changes were particularly similar late in the session. The few differences that do appear occurred early in the session and do not represent a systematic difference in responding on the two operanda. That is, the rate of keypressing sometimes increased more quickly and sometimes more slowly than did that for leverpressing. The strength of the relation between 
the rates of responding during the two components of each concurrent schedule was assessed by calculating a Pearson correlation coefficient. The coefficients were greater than .80 for all schedules and all coefficients were statistically significant $(p<.002$ : a chi-square test with $1 d f$ ).

To illustrate the implications of these results for the quantification of concurrent schedules responding, the data have been fit to the generalized matching law (GML, Baum, 1974), a commonly cited quantitative theory. Figure 2 presents the sensitivity to reinforcement ( $S$, circles) and bias (B, triangles) parameters, as well as the proportion of the variance accounted for by the GML (PV, inverted triangles), as a function of successive 5min intervals in the session. The version of the GML tested here states that the ratios of the rates of responding during the components of concurrent schedules will equal a constant (bias) multiplied by the ratio of the rates of reinforcement obtained from those components raised to a power (undermatching or sensitivity to reinforcement). The values plotted in Figure 2 were calculated by applying a linear least-squares curve-fitting technique to the logarithms of the ratios of the rates of key to leverpressing in each 5-min interval as a function of the logarithm of the ratios of the rates of reinforcement obtained by key- and leverpressing. Limitations on the present data- recording apparatus did not allow separate recordings of the rates of reinforcement that were obtained on each operandum during each 5-min interval. Therefore, the ratio of average reinforcement rates over the entire session for key- and leverpressing was used as the independent variable for each 5-min interval. These calculations were based on the mean of all subjects over the last five sessions of training with each schedule.

Figure 2 shows that the GML fit the data well: The proportion of the variance accounted for was always greater than 0.90 . The median sensitivity parameter (0.78) was similar to the median sensitivity for respond-

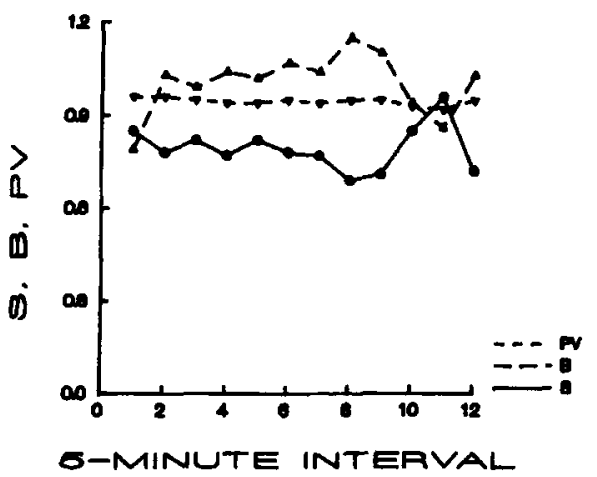

Figure 2. The sensitivity to reinforcement (S, circles) and bias (B, triangles) parameters of the generalized matching law (Baum, 1974), as well as the proportion of the variance in the data accounted for (PV, inverted triangles) by the generalized matching law, as a function of successive 5-min intervals in the session. The method of calculating these values is described in the text. ing reported in some past studies of concurrent schedules that used different operanda in the two components (median $=0.70$ in Wheatley \& Engberg, 1978; median $=0.87$ in Davison \& Ferguson, 1978). Little bias was apparent in Figure 2 for either the key or lever (bias parameter close to 1.0 ). Past studies have reported bias when subjects respond on two-operanda concurrent schedules (Davison \& Ferguson, 1978; Hanson \& Green, 1986; Wheatley \& Engberg, 1978), but all of these studies examined pigeons responding on concurrent keypeck treadlepress schedules. Therefore, these past results may not be relevant to interpreting the bias parameter from the present study, in which rats pressed levers or keys. Although the size of both the bias and the sensitivity parameters shown in Figure 2 varied somewhat from interval to interval, no systematic withinsession changes occurred consistently for individual rats for either parameter.

\section{EXPERIMENT 2}

In Experiment 2, we assessed the generality of the conclusions reached in Experiment 1. In Experiment 2, pigeons pecked a key or pressed a treadle for mixed grain on several concurrent schedules. Again, different within-session patterns of responding in each component of the schedule were encouraged by the use of different operanda and different rates of reinforcement.

\section{Method}

Subjects. The subjects were four experimentally experienced pigeons that had pecked keys for food reinforcers on other operant procedures. Pigeons were maintained at approximately $85 \%$ of their free-feeding weights by postsession feedings.

Apparatus. The apparatus was a two-key, two-treadle experimental enclosure, measuring $27.0 \times 30.0 \times 29.5 \mathrm{~cm}$. The keys were 2.5 -cm-diameter Plexiglas panels that appeared $4 \mathrm{~cm}$ below the ceiling and $12.5 \mathrm{~cm}$ from each other. The left key was $6.0 \mathrm{~cm}$ from the left wall; the right key was $6.5 \mathrm{~cm}$ from the right wall. Each key was operated when a force of approximately $0.25 \mathrm{~N}$ was applied to its center. A treadle was located $15.5 \mathrm{~cm}$ below each of the keys. Each treadle consisted of a 5-cm-diameter disk held in a resting position $1 \mathrm{~cm}$ above the floor by an aluminum strip which connected it to the wall containing the keys. The aluminum strips were $6.5 \mathrm{~cm}$ long and $1 \mathrm{~cm}$ wide. The treadles operated when a force of approximately $0.30 \mathrm{~N}$ was applied to their centers. A $5 \times$ $4 \mathrm{~cm}$ opening allowed access to a magazine that contained mixed grain. The magazine was located $12.5 \mathrm{~cm}$ from the right wall and $3 \mathrm{~cm}$ above the floor. A light behind a $1-\mathrm{cm}$-diameter Plexiglas panel served as a houselight and was $0.5 \mathrm{~cm}$ from the left wall and $0.5 \mathrm{~cm}$ from the ceiling. The experimental enclosure was located in a sound-attenuating chamber. A ventilating fan masked extraneous noises. Experimental events were controlled and data were recorded by a SYM microcomputer located in another room.

Procedure. The subjects had pecked keys in previous experiments. Therefore, pressing the right treadle was trained by using a successive approximations procedure.

During the first experimental condition, pecking the left key and pressing the right treadle each produced reinforcers according to a VI 60-sec schedule. Reinforcers were $5 \mathrm{sec}$ of access to mixed grain, scheduled according to a 25-interval Fleshler and Hoffman (1962) series. The session timer stopped during reinforcement. 
The left key was illuminated by red light, and the key above the right treadle was illuminated by blue light. The houselight also was illuminated throughout the session, except that the key and houselights were extinguished during reinforcement. When pigeons had responded on the concurrent VI $60-\mathrm{sec}$ VI $60-\mathrm{sec}$ schedule for 30 sessions, they were placed on the sequence of concurrent schedules used in Experiment 1. The schedule listed first refers to the schedule obtained by pecking the key. The schedule listed second refers to the schedule obtained by pressing the treadle. All other procedural details were identical to those in Experiment 1 .

\section{Results and Discussion}

The schedules exerted good control over behavior. Rates of keypecking and treadlepressing increased with increases in the programmed rates of reinforcement, but declined at the highest programmed rates. Average rates $( \pm S E M)$ of keypecking were $18.0(5.7), 25.5(5.4), 21.3$ (3.0), $24.2(4.7), 7.1(1.0)$, and $11.2(4.0)$ responses per minute, respectively, for the VI $15-\mathrm{sec}$, VI $30-\mathrm{sec}$, VI 60-sec, VI 60-sec, VI 120-sec, and VI 240-sec components. Average rates of treadlepressing $( \pm S E M)$ were $9.2(2.7), 13.3(2.5), 10.3(2.5), 3.4(1.4), 5.4(1.0)$, and $0.8(0.2)$ responses per minute, respectively, for the components listed above. As stated earlier, decreases in responding at high programmed rates of reinforcement are frequently observed and are consistent with several theories.

Figure 3 presents the mean percentage of total-session key pecks (circles) and treadlepresses (triangles) during successive 5-min intervals for all subjects responding on each concurrent schedule. Percentages were calculated in the same manner as in Experiment 1 (see Figure 1). Each graph presents the results for a different schedule.

Keypecking and treadlepressing sometimes changed within sessions during concurrent keypeck treadlepress schedules. Repeated measures ANOVAs of the response rates for individual subjects during successive 5-min intervals identified significant within-session changes in responding only for keypressing during the first concurrent VI 60 -sec VI 60-sec schedule $[F(11,33)=2.61, p<$ $.016]$, the concurrent VI $240-\mathrm{sec}$ VI 15-sec schedule $[F(11,33)=2.96, p<.008]$, and the concurrent VI 120 sec VI 30 -sec schedule $[F(11,33)=3.57, p<.002]$. Within-session changes in responding were significant for treadlepressing during the concurrent VI 120-sec VI $30-\sec$ schedule $[F(11,33)=2.98, p<.007]$.

The forms of the within-session changes were more variable across subjects for the pigeons than they were for rats. Differences in response patterns for different subjects may have been responsible for the lack of significant effects, even if responding did change significantly within sessions for individual subjects. This possibility was tested by applying one-way (5-min interval) repeated measures ANOVAs to rates of keypecking or treadlepressing by individual pigeons during the last five sessions for which each schedule was available. Rates of keypecking changed significantly within the session for most individual subjects $[F \mathrm{~s}(11,44)>2.00, p \mathrm{~s}<.05]$. Tests failed to reach significance only for responding by
Subject $7[F(11,44)=0.82, p<.623]$ and Subject 130 $[F(11,44)=1.52, p<.158]$ in the VI 240 -sec component, for Subject $1413[F(11,44)=1.72, p<.100]$ in the VI 15-sec component, and for Subject $130[F(11,44)=$ $1.65, p<.119]$ in the VI 30 -sec component of a concurrent schedule. Rates of treadlepressing always changed significantly within the session for Subject $7[F \mathrm{~s}(11,44)>$ $2.86, p s<.007]$ and Subject $16[F \mathrm{~s}(11,44)>3.09, p s<$ $.004]$, but never changed significantly for Subject 1413 $[F \mathrm{~s}(11,44)<1.77, p \mathrm{~s}>.089]$. Responding changed significantly during some components for Subject 130 [the first VI 60 -sec component, $F(11,44)=2.71, p<.009$; the VI 30-sec component, $F(11,44)=4.91, p<.001$; the VI 120-sec component, $F(11,44)=2.46, p<.017$; and the second VI 60 -sec component, $F(11,44)=2.29, p<$ $.026]$, but did not change significantly within sessions for others [the VI 15-sec component, $F(11,44)=1.11$, $p<.378$; and the VI 240-sec component, $F(8,32)=$ $0.74, p<.658]$. Different degrees of freedom appear for Subject 130 responding during the VI 240 -sec schedule because this subject did not respond during some 5-min intervals; statistical tests were computed over only those intervals during which a subject responded. When significant changes in responding occurred, these changes were almost always systematic, as was indicated by a significant $(p<.05)$ linear or quadratic polynomial contrast.

Pearson correlation coefficients were calculated to assess how similar within-session changes in responding were for keypecking and treadlepressing during each concurrent schedule. Except for the concurrent VI 240sec VI 15-sec schedule (Pearson coefficient $=-.155$, $p<.631)$, all coefficients were positive and statistically significant $(p<.05)$ by a chi-square test with $1 d f$. All of the significant coefficients (except that for the second concurrent VI 60-sec VI 60-sec schedule [coefficient $=$ .612]) were greater than .80 . Therefore, although some differences in the within-session patterns of responding for keypecking and treadlepressing appear in Figure 3, the within-session changes were basically similar for the two responses.

Figure 4 presents the sensitivity to reinforcement (S, circles) and bias (B, triangles) parameters of the GML, as well as the proportion of the variance in the data accounted for by the GML (PV, inverted triangles), as a function of successive 5-min intervals in the session. The values plotted in Figure 4 have been calculated and reported in the same manner as those for Figure 2. In all cases, the rates of responding and reinforcement for keypecking were divided by the comparable values for treadlepressing.

The GML described these data well, usually accounting for a proportion of the variance in the data that was greater than .80 . Responding was biased (bias $>1.0$ ), and the median sensitivity to reinforcement was .57. The finding of bias is consistent with the results of past studies of concurrent keypeck treadlepress behavior (Davison \& Ferguson, 1978; Hanson \& Green, 1986; Wheatley \& Engberg, 1978), but the sensitivity parameter is 


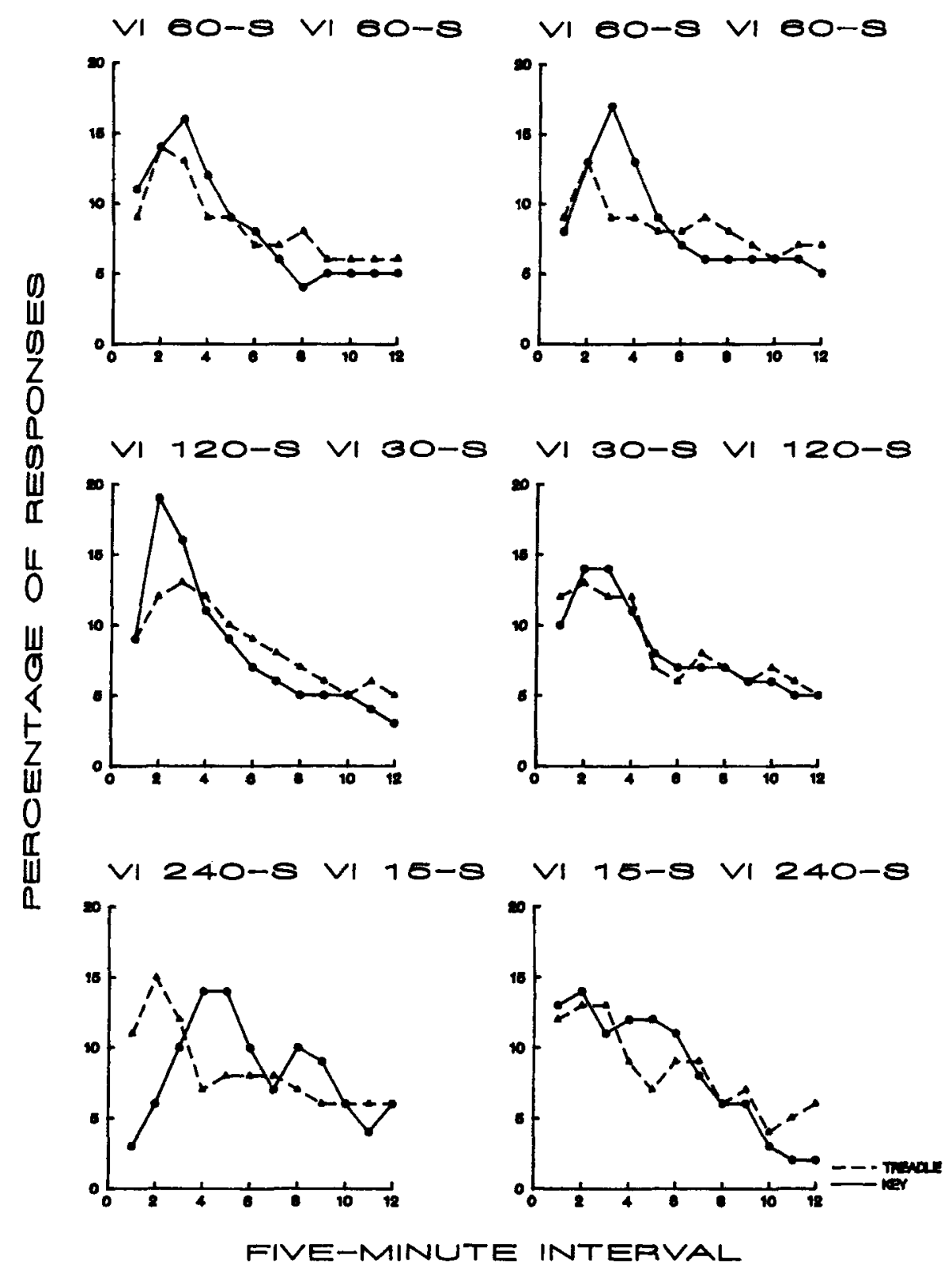

Figure 3. The percentage of the total-session keypecks (circles) and treadlepresses (triangles) during successive 5-min intervals for the mean of all subjects responding on each schedule in Experiment 2. Percentages have been calculated as for Figure 1. Each graph presents the results for a different schedule.

smaller than that usually reported during these schedules (median $=0.87$ in Davison \& Ferguson, 1978 ; median $=$ 0.93 in Hanson \& Green 1986; median $=0.70$ in Wheatley \& Engberg, 1978). The factors that produced the smaller sensitivity are not know. However, the size of this parameter is known to be sensitive to the choice of procedural details, such as the length of the changeover delay (cf. McSweeney, 1978).

The bias parameter increased somewhat and then decreased within the session. The undermatching parameter was high early in the session, but it decreased as the session progressed. The proportion of the variance accounted for by the GML also decreased somewhat within the session. However, these within-session changes were not statistically significant. The results of Friedman nonparametric analyses of variance by ranks applied to the parameters estimated for individual subjects were as follows: Friedman test statistic $=13.90, d f=11, p<.234$ for bias; Friedman test statistic $=12.90, d f=11, p<$ .300 for sensitivity; Friedman test statistic $=14.04, d f=$ $11, p<.231$ for the proportion of the variance in the data. Nonparametric statistics were used because the 


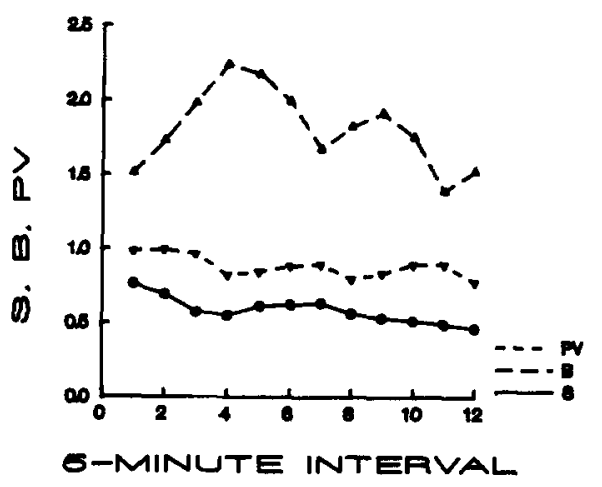

Figure 4. The sensitivity to reinforcement (S, circles) and bias (B, triangles) parameters of the generalized matching law (Baum, 1974), as well as the proportion of the variance in the data accounted for by the generalized matching law (PV, inverted triangles), as a function of successive 5-min intervals in the session for Experiment 2. The parameters and fit of the generalized matching law were calculated as for Figure 2.

values of these variables cannot be assumed to be normally distributed.

\section{GENERAL DISCUSSION}

Responding usually decreased or increased and then decreased within sessions when rats responded on concurrent keypress leverpress schedules and when pigeons responded on concurrent keypeck treadlepress schedules. Responding failed to change significantly within sessions only for rats pressing keys on the VI $240-\mathrm{sec}$ component and for some individual pigeons pecking keys or pressing treadles on each of the concurrent schedules. These results increase the generality of within-session changes in responding. Systematic changes have not been reported previously for subjects responding on concurrent schedules that employ different operanda in the two components.

Similar within-session changes in responding were observed during the two components of the present concurrent schedules. This conclusion was reached even when the two components provided substantially different rates of reinforcement and employed different operanda to produce reinforcers. As argued earlier, there are reasons to believe that differences in the rates of reinforcement and in the choice of operandum should create differences in the within-session patterns of responding.

The finding of similar within-session patterns for two components of a concurrent schedule has implications for the quantification of responding. In particular, this outcome implies that within-session changes will not distort the predictions of theories that describe the ratio of the rates of responding in concurrent schedules. As indicated in Figures 1 and 3, the percentages of totalsession responses emitted at a particular time in the session are similar for both components of a concurrent schedule. Equation 1 summarizes this finding: $P_{k i}$ and $P_{t i}$ are the number of keypecks and treadlepresses, respec- tively, during the $i$ th interval in the session. Equation 2 follows from Equation 1; it shows that the ratio of pecking to pressing in the $i$ th interval will equal the ratio of response rates calculated over the session as a whole. To further illustrate this point, the present experiments showed that neither the size of the parameters of the GML, nor its goodness of fit, changed systematically within experimental sessions. The GML provides one example of a theory that attempts to predict the ratio of the rates of responding.

$$
\begin{aligned}
\frac{P_{k i}}{\Sigma P_{k i}} \times 100 & =\frac{P_{t i}}{\Sigma P_{t i}} \times 100 \\
\frac{P_{k i}}{P_{t i}} & =\frac{\Sigma P_{k i}}{\Sigma P_{t i}}
\end{aligned}
$$

In future experiments, this conclusion should be verified by the use of concurrent schedules with a wide range of different responses, reinforcers, and COD durations. The parameters and fit of the GML should be determined for the time spent responding, as well as for response rates. Experiments should also examine the fit of the GML when the ratio of the rates of reinforcement actually obtained during successive 5-min intervals is used. Because of equipment limitations, in the present study we used the ratio of the rates of reinforcement calculated over the entire session as the independent variable for all 5-min intervals. This ratio may have provided a good estimate of the ratios obtained at different times in the session, because the responding that produced these reinforcers changed similarly within the session for the two components. However, within-session changes in the ratios of rates of reinforcement deserve study in their own right.

The present results provide insight into the factors that produce within-session changes in responding. The finding that responding changes systematically when subjects respond on concurrent schedules rules out the idea that explicit discriminative stimuli are needed in order to produce these changes. Most past studies of within-session changes have employed multiple schedules that use discriminative stimuli to signal the components. Such stimuli might provide an external cue to time that is needed for responding to change systematically. The present results and those of McSweeney, Roll, and Weatherly (1994) for subjects responding on fixed interval (FI), variable ratio (VR), and differential reinforcement of low rates of responding (DRL) schedules show that within-session changes can occur even when explicit discriminative stimuli are not presented.

If it is assumed that key- and lever- or treadlepressing employ different muscles that should warm up and fatigue at different rates, the present results suggest that factors related to responding, such as muscular warm-up or fatigue, contribute little to within-session changes. The within-session patterns of responding should have differed for two components that employed different muscles if factors related to responding produced these 
patterns. The results of some past studies support a similar conclusion. For example, within-session changes were larger for VR than for FI and DRL schedules (McSweeney, Roll, \& Weatherly, 1994), even though subjects responded at similar rates on the VR and FI schedules but more slowly on the DRL schedules. If fatigue produced the within-session changes, these changes should have occurred similarly for the FI and VR schedules and more slowly for the DRL schedules.

Because of the potential importance of the conclusion that factors related to responding contribute little to within-session changes in responding, the present experiment should be replicated with the use of concurrent schedules in which the force required to operate the operandum differs systematically for the two components. The interpretation of the results of such a study would not have to rely on the assumption that responses that employ different muscles should warm up and fatigue at different rates.

Finally, the present results suggest that the mechanism that produces within-session changes in responding integrates the reinforcers obtained from the two components of the concurrent schedule. Past studies of responding during simple and multiple schedules have shown that changes in the rates of reinforcement alter the within-session pattern of responding (McSweeney, 1992; McSweeney, Roll, \& Cannon, 1994; McSweeney, Roll, \& Weatherly, 1994). The present experiments showed that the within-session changes did not differ for the two components of the concurrent schedules even when those components provided different rates of reinforcement. This suggests either that within-session changes during concurrent schedules are not sensitive to changes in rates of reinforcement or that the mechanism that controls these within-session changes integrates the reinforcers obtained from the two components. For example, the sum of the reinforcers obtained from the two components would be the same for both components and a mechanism based on this sum would produce similar changes in both components. At this time, it is more parsimonious to assume that the mechanism integrates reinforcers than to distinguish between within-session changes during multiple and simple schedules that are sensitive to the rate of reinforcement and those during concurrent schedules that are not. However, a future experiment is needed in order to show that within-session changes during concurrent schedules are, in fact, sensitive to changes in the rates of reinforcement. The sum of the rates of reinforcement obtained from the two components should be varied over a wide range, and changes in the within-session patterns of responding should be observed.

\section{REFERENCES}

BAUM, W. M. (1974). On two types of deviation from the matching law: Bias and under-matching. Journal of the Experimental Analysis of Behovior, 22, 231-242.

BAUM, W. M. (1981). Optimization and the matching law as accounts of instrumental behavior. Journal of the Experimental Analysis of Behavior, 36, 387-403.

Davison, M., \& Ferguson, A. (1978). The effects of different component response requirements in multiple and concurrent schedules. Journal of the Experimental Analysis of Behavior, 29, 283295

Dougan, J. D., \& McSWEENEY, F. K. (1985). Variation in Herrnstein's $\mathrm{r} 0$ as a function of alternative reinforcement rate. Journal of the Experimental Analysis of Behavior, 43, 215-223.

FLESHLER, M., \& HofFMAN, H. S. (1962). A progression for generating variable-interval schedules. Journal of the Experimental Analysis of Behavior, 5, 529-530.

Hanson, J., \& GREEN, L. (1986). Time and response matching with topographically different responses. Animal Learning \& Behavior, 14, 435-442.

HERRNSTEIN, R. J. (1970). On the law of effect. Journal of the Experimental Analysis of Behavior, 13, 243-266.

MCSWEENEY, F. K. (1978). Prediction of concurrent keypeck treadlepress responding from simple schedule performance. Animal Learning \& Behavior, 6, 444-450.

MCSWEENEY, F. K. (1992). Rate of reinforcement and session duration as determinants of within-session patterns of responding. Animal Learning \& Behavior, 20, 160-169.

MCSWEeney, F. K., HatField, J., \& Allen, T. M. (1990). Withinsession responding as a function of post-session feedings. Behavioural Processes, 22, 177-186.

MCSWEENEy, F. K., \& Hinson, J. M. (1992). Patterns of responding within sessions. Journal of the Experimental Analysis of Behavior, 58, 19-36.

MCSWEENEY, F. K., \& MELVILLE, C. L. (1991), Behavioral contrast as a function of component duration for leverpressing using a withinsession procedure. Animal Learning \& Behavior, 19, 71-80.

MCSWEENEY, F. K., \& RoLL, J. M. (1993). Responding changes systematically within sessions during conditioning procedures. Journal of the Experimental Analysis of Behavior, 60, 621-640.

MCSweEney, F. K., Roll, J. M., \& CanNon, C. B. (1994). The generality of within-session patterns of responding: Rate of reinforcement and session length. Animal Learning \& Behavior, 22, 252-256.

MCSWEeney, F. K., Roll, J. M., \& WeatherLy, J. N. (1994). Withinsession changes in responding during several simple schedules. Journal of the Experimental Analysis of Behavior, 62, 109-132.

Mosso, A. (1906). Fatigue (M. Drummond, Trans.). New York: Putnam.

STADDON, J. E. R. (1979). Operant behavior as adaptation to constraint. Journal of Experimental Psychology: General, 108, 48-67.

WheATLEy, K. L., \& ENGBERG, L. A. (1978). Choice performance in several concurrent key-peck treadle-press reinforcement schedules. Journal of the Experimental Analysis of Behavior, 29, 181-190.

(Manuscript received April 1, 1994; revision accepted for publication July 10, 1994.) 